\title{
6 \\ Procedural Justice in Police Action
}

Previous research on citizens' subjective experiences in their encounters with police has relied almost exclusively on surveys of citizens, and so extant evidence leaves as an open question the extent to which citizens' reported perceptions are congruent with what officers actually do (and do not do) in those interactions. In addition to surveying citizens who had contacts with the Schenectady police, we observed a subset of the encounters about which citizens had been interviewed, relying on the video and audio recordings of police-citizen encounters that are routinely made as a matter of police department procedure. In this chapter, we summarize findings about the procedural justice with which Schenectady police were observed to act, based on the judgments of trained independent observers who applied a standardized coding protocol to measure officers' behavior.

We build on previous efforts to measure police behavior, in general, and officers' procedural justice behavior in particular, and so first we review previous research that has informed our study. Then we explain how we conducted the observations and, on that basis, measured procedural justice, and we summarize our observations in those terms. We also present information on other pertinent forms of police behavior, and on features of the context in which officers act-for example, the resistance that citizens offer. Finally, we estimate the parameters of a model of officers' procedural justice in order to better understand the factors in the immediate situation that influence the procedural justice with which officers act. 


\section{MEASURING PROCEDURAL JUSTICE BEHAVIOR}

Notwithstanding the volume of research on police behavior that has accumulated over the past five-plus decades, we know very little about the procedural justice with which police routinely exercise their authority, except insofar as citizens' subjective experiences are reliable indicators. Official police records do not open a window on these aspects of police performance, of course; offense and arrest reports do not normally include information on officers' adherence to the principles of procedural justice, and even if they did, officers' self-reports of these behaviors would not generally be considered reliable for scientific purposes. But even though a number of studies have provided for direct, in-person observation of police officers at work in its natural setting, with copious data on police-citizen interactions, this research has dwelled much more on the forms of authority that officers exercise and the circumstances under which that authority is applied than on the procedural justice with which authority is wielded.

Furthermore, survey-based measures of citizens' judgments about procedural justice are much better developed than observation-based measures of officers' overt behavior. It is not only that most previous research using systematic social observation of police did not use procedural justice concepts, as such, to guide the construction of observation instruments. Part of the challenge, we surmise, stems from the fact that the distinctions among the four widely accepted elements of procedural justice-voice/participation, quality of interpersonal treatment, trustworthy motives, and neutrality-are not as clearly demarcated in forms of police action as they are in citizens' interpretations of their experiences. Tom Tyler explains, for example, that "authorities can encourage people to view them as trustworthy by explaining their decisions and justifying and accounting for their conduct in ways that make clear their concern about giving attention to people's needs." But the same actions by police-explaining their decisions-from which citizens can infer trustworthy motives also offer transparency, from which citizens can infer neutrality: "evidence of factuality and lack of bias suggest that those procedures are fair" (Tyler 2004, 94). ${ }^{1}$ This may help to account for the lack of a consensus among researchers about the translation of officers' actions into procedural justice constructs.

We review this small but important body of empirical evidence here, and as much as possible build on that foundation. All of this research is based on systematic social observation (SSO) of police. ${ }^{2}$ Albert Reiss Jr. pioneered the application of SSO to the study of police in 1966, and the instruments that Reiss developed have since been elaborated through several major studies and a number of smaller-scale, more focused studies. SSO has employed in-person observation of patrol officers as they perform their work in its natural setting, with researchers accompanying selected officers during their regular work shifts. SSO is systematic in two respects. First, the selection of officers to be observed is subject 
to probability sampling, so that inferences from analytic results can be drawn with the benefit of known statistical properties. Second, observers are all guided in their observation by a single structured coding protocol that is formulated prior to the field research and directs observers' attention to specified features of police work; thus their observations are captured in the form of standardized measurement categories, which are quantifiable and replicable. This research has been invaluable in describing and understanding how often and under what circumstances officers use various forms of police authority, including their authority to make arrests, use physical force, and stop, detain, and search citizens.

SSO research on the police has been less informative about the procedural justice with which police authority is wielded, but some advances have been made in putting observational data to use in measuring procedural justice, and the development of the observation instruments for coding the Schenectady encounters capitalized on the rich tradition of SSO-based research and on the recent advances with respect to measuring procedural justice. One study examined disrespectful behavior by officers toward citizens, which is of course a form of procedural injustice. Several studies have attended to the role of procedural justice in shaping citizen compliance with police requests, and the measures formed for these studies are instructive. One of those studies not only analyzed the data for which the structured observation instrument provided, but in addition exploited narrative accounts of police-citizen encounters prepared by observers, to derive indicators of procedural justice for which coding instruments did not provide. Finally, one recent study (Jonathan-Zamir et al. 2015) expressly built indicators of procedural justice into its coding instrument. ${ }^{3}$

\section{Disrespect}

In 2002, Stephen Mastrofski, Michael Reisig, and John McCluskey analyzed data collected in Indianapolis and St. Petersburg, Florida, for the Project on Policing Neighborhoods (POPN) to describe and account for police disrespect toward citizens. They found that in 9 percent of the observed police-citizen encounters involving suspected offenders, the officer was disrespectful to the citizen. Such disrespect encompassed "name calling, derogatory statements about the citizen or the citizen's family, belittling remarks, slurs, cursing, ignoring the citizen's questions (except in an emergency), using a loud voice or interrupting the citizen (except in an emergency), obscene gestures, or spitting" (Mastrofski et al. 2002, 529-30). ${ }^{4}$ They also found that in many of these instances, the officer was responding in kind to disrespect by the citizen; only 4 percent of the respectful citizens were subjected to "unprovoked" disrespect by police. Moreover, this study also found that officers did not respond in kind to displays of disrespect by citizens two-thirds of the time. Officers in these cities more often than not maintained a professional (i.e., civil) demeanor even in the face of citizens' discourtesy. 
This study is very helpful, to be sure, but we should not mistake police disrespect for procedural justice. Disrespect is a form of only procedural injustice, and officers are not respectful by virtue of not being disrespectful; they can be neither disrespectful nor respectful. Police are respectful when, for example, they use titles (e.g., "mister") or other terms of deference (e.g., "sir" or "ma'am") to address citizens. In addition, of course, police performance in their encounters with citizens can be described in terms of other elements of procedural justice: actively listening to citizens, explaining what they are doing and why, expressing concern or sympathy for citizens' situations, and asking citizens for their accounts of events.

\section{Police Requests and Citizen Compliance}

Observations in Richmond, Virginia (Mastrofski et al. 1996), in Indianapolis and St. Petersburg, Florida (McCluskey et al. 1999; McCluskey 2003), and in Cincinnati (Dai et al. 2011) have formed the basis for analyses of the procedural justice of police actions as a factor that conditions the success with which police obtain citizens' compliance when they make requests of citizens. The requests made of citizens were for them to leave the scene or leave another person alone, discontinue their disorderly behavior, or discontinue their illegal behavior. All but one of these studies relied on the data coded by observers according to the observation instrument, and so the indicators of procedural justice were somewhat limited. For example, the initial study (Mastrofski et al. 1996) and the replication of that study (McCluskey et al. 1999) both operationalized voice or participation in terms of whether a citizen rather than police initiated the encounter (e.g., by flagging down the officer in the field, or placing a phone call to 911 or another police number); this of course leaves open the extent to which the citizen is given an opportunity by the officer at the scene to tell his/her story. The quality of interpersonal treatment was measured only as police disrespect toward the citizen, and trustworthy motives were captured only as police treating the citizen as having a situational status other than that of suspected offender. Mengyan Dai et al. (2011) did somewhat better-for example, voice reflected officers' reactions to citizens' requests-but was nevertheless limited by the coding instrument, which was not designed with procedural justice in view.

McCluskey (2003) escaped the limitations of the coding instrument by tapping the narratives prepared by observers to capture elements of the interactions that were not coded originally, and he thus was able to construct indicators that individually enjoyed greater face validity and that together better represented the range of actions that comprise procedural justice. So it was that McCluskey took into account displays of respect as well as disrespect, whether officers sought information from citizens and explained their actions. He found that, in encounters in which police requested compliance from citizens, displays of respect were nearly twice as common as disrespect, although neither respect nor disrespect was 
displayed in about three-quarters of the encounters. Citizens were given "voice"that is, communicated facts about the situation to police-about one-third of the time, and had their voice terminated-officers "silenced" the citizen-in only 4 percent of the encounters. In 12 percent of the encounters, officers explained to citizens that the circumstances of the case provided them with authority to invoke the law of which they chose not to avail themselves.

Since the focus of these studies was on citizen compliance, and not on procedural justice as such, they analyzed only the subsets of encounters in which officers made a request for citizen self-control, and so of course they shed no light on the procedural justice with which police act more generally. The subsets were not large. McCluskey 2003, for example, focused mainly on 1,022 of the 5,623 citizens who interacted with observed officers across the two research sites. The degree to which officers' behavior in these encounters is representative of their behavior more generally is impossible to say.

We would also note that in the context of this analytical framework, citizens' interpretations of the justice with which police act are presumptively intervening but unmeasured variables, and we infer that associations between police actions, on the one hand, and citizen (non)compliance, on the other hand, reflect an effect of the former on the latter that is mediated by the subjective experience of citizens. Overall, citizens complied in 69 percent of the encounters. But compliance was nearly twice as likely when police showed respect, and about 60 percent as likely when they showed disrespect, as when police displayed neither respect nor disrespect. The termination of voice cut compliance rates by half, while seeking information about the situation doubled compliance.

\section{Procedural Justice}

Tal Jonathan-Zamir, Stephen Mastrofski, and Shomron Moyal (2015) recently completed a small-scale observational study whose purpose was to develop and validate an instrument with which the procedural justice of police behavior could be measured. They built, as we did, on the protocols of previous observational studies of the police, but they also added items to the observation form to more completely describe procedural justice. Moreover, they offer a particularly careful and thorough assessment of previous studies-including those discussed aboveto advance the discussion about how to operationalize procedural justice in terms of data on police behavior. We should examine their study very closely, for it is the only previous effort to translate structured observations into a full complement of measures of procedural justice. ${ }^{5}$

Their study provided for observations of the pseudonymous "Everdene" police, who serve a small suburban city. Four trained observers accompanied twelve patrol officers on thirty-five work shifts, capturing information on 233 police-citizen encounters with 319 citizens. ${ }^{6}$ From these data they construct a measure of behavior 
in each of the four domains of procedural justice and, in addition, combine those measures to form an overall index of procedural justice.

Jonathan-Zamir and her colleagues argue for the use of formative measures of procedural justice in action. They maintain that although survey items are properly treated as various reflections of an underlying perceptual construct when citizens' subjective experiences are measured, such that the items can be expected to exhibit strong associations, officers' behaviors are not the manifestations or products of an underlying construct. Instead, they contend, officers' behaviors form a measure of procedural justice: "because measures of procedural justice are not expected to develop from a single latent variable, and the various procedurally just behaviors are viewed as tapping different facets of the construct, they are not expected to be intercorrelated and are not interchangeable" (Jonathan-Zamir et al. 2015, 852). We agree with this assessment, and we would add as further justification the situationally contingent nature of police action, as a consequence of which we might expect to observe in different situations different manifestations of neutrality or trustworthy motives or quality of treatment.

For each of the four procedural justice domains, Jonathan-Zamir et al. formed a five- or six-point scale. Two of the scales (neutrality and trustworthy motives) were each a simple sum of binary individual actions, such as explaining why police became involved and explaining the choice of resolutions. One (participation) was in effect a weighted sum, weighting officer's requests for information and citizens' provision of information by the attentiveness with which police listened. And one scale (dignity) captured degrees of respect and disrespect, respectively, based on the duration or frequency of such behaviors, though disrespect was so infrequent that such distinctions were needed only for respect. The four scales were combined to form a single (unweighted) index of procedural justice.

They found a fairly high level of participation, with 43 percent of the policecitizen interactions at the high end of the scale (4), and an additional 25 percent nearly so high (3). This would imply that officers asked for information and/or citizens provided information, with officers listening passively or actively. Neutrality exhibited the opposite pattern, with 38 percent of the interactions in the "very low" category and an additional 43 percent in the "low" category. Dignity was more or less normally distributed, with only 5 percent of the interactions at the low (disrespectful) end and 6 percent at the high end (at which the officer showed "dominant" respect). Finally, the distribution of trustworthy motives resembled that of the neutrality scale, with nearly half of the interactions at the low end. The four scales were all positively intercorrelated, though fairly modestly, with correlations ranging from .10 to .30 . Each was correlated with the overall index, with correlations ranging from .59 to .70 .

Jonathan-Zamir et al. (2015) estimated the correlations of the index of procedural justice and each of its subscales with the "citizens' behavioral manifestations 
of satisfaction with the police," as judged by the observers. In this way they were able to assess the criterion-related validity of their measure of procedural justice. Their observers were able to assess citizen satisfaction in about half of the cases, and among those, they found a substantial association between satisfaction and procedural justice overall. They also found statistically significant associations between satisfaction and three of the four subscales.

\section{SCHENECTADY OBSERVATIONS}

The Schenectady Police Department's use of in-car cameras afforded us an opportunity to collect observational data on police-citizen encounters, and in that way to not rely exclusively on survey data to describe officers' procedural justice. At the conclusion of the police services survey, we sampled from among incidents about which we had completed an interview with the citizen, and we requested copies of the video/audio files, with which the Schenectady Police Department obliged us.

To our knowledge only one previous effort has been made to conduct "armchair" observation of police by using video recordings of police-citizen encounters, rather than conducting in-person observation, to collect systematic information about police actions for analytical purposes (Dixon et al. 2008). That study focused on traffic stops only, and in addition, it was designed to examine the influences of citizen and police officer race on communication patterns, and particularly "communication accommodation"; it did not extend to the wide range of citizen and officer behaviors on which SSO of police has dwelled, or on procedural justice as such. However, this study affirmed the feasibility of coding police-citizen interactions from video and audio recordings, and the theoretical constructs and operational measures that it formulated were useful additions to extant SSO protocols in capturing how police authority is exercised.

Thus we drew from both lines of research to form observation instruments that are rooted in previous inquiry but also suited to the measurement of procedural justice. Like previous SSO research, we provided for information on the encounter as a whole, for example, the type of location in which the interaction transpired, and the nature of the problem that was the focus of attention. The instruments departed in some respects from previous SSO instruments, however, insofar as we were particularly interested in the officers' behavior toward one citizen in each encounter-the citizen who was the respondent to our survey, and on whose subjective experience we wanted to estimate the effects of officers' behavior. Hence we designated as the "primary citizen" the citizen whose name appeared in the police record, and whom we interviewed after his/her contact with the police, and we instructed observers to try in each incident to identify the primary citizen and code items accordingly. For each incident, observers 
TABLE 2 Observation Instruments

\begin{tabular}{l} 
Encounter-level \\
\hline primary citizen $x$ primary officer \\
primary citizen $x$ other officer(s) \\
other citizen(s) x primary officer \\
other citizen(s) x other officer(s)
\end{tabular}

were provided with some identifying information to facilitate this task: the primary citizen's name, race, and sex, as well as the nature of the contact (arrest, call, field interview). Citizens other than the primary citizen were treated as a single group for coding purposes. The "primary officer" was the officer who was assigned to the patrol unit that was dispatched to a call, or whose name appeared on the arrest report or field interview card, and whose microphone recording was included with the video; this was the officer who is analogous to the officer to whom an observer would be assigned in the context of an in-person SSO study. Other officers, like other citizens, were treated as a single group. Items concerning the primary citizen's dyadic interaction with the primary officer comprised one instrument, and items concerning the primary citizen's interaction with other officers (if any) at the scene comprised a separate instrument. (See table 2.) Other citizens' interactions with the primary and other officers, respectively, were captured in less detail on separate instruments. Thus we can describe the interaction of the primary citizen with the primary officer and with other officers; we can likewise describe the interaction of other citizens with the primary officer and with other officers.

Based predominantly on the observation instruments used for the Project on Policing Neighborhoods (POPN) in 1996-97, the instruments captured information on requests that citizens made of officers and how police responded to those requests, requests or commands by officers and how citizens responded to those requests or commands, officers' use of police authority (e.g., searching or frisking the citizen, the use of physical force, arrests, citations), and forms of disrespect by citizens and/or officers. In addition, observers were prompted to make summary characterizations of selected features of the interaction, such as how much patience officers exhibited, how well officers listened to citizens, and how much consideration the officers showed for the citizens' point of view.

Each sampled incident was assigned to two observers, ${ }^{7}$ who independently watched and listened to the recorded incident, took notes, and worked through the computer-guided data entry process, clicking on selected response options or, in some instances, entering information in a free-field format. ${ }^{8}$ An observer could watch all or a portion of any incident multiple times as needed. 


\section{Sampling}

The major SSO studies of the police have sampled patrol units, to which observers are assigned for the duration of an entire work shift, such that the observed policecitizen encounters are those in which the officer assigned to that unit became involved. Sampling has been structured spatially, by police beats, and temporally, by work shifts or tours of duty; normally, observations are concentrated somewhat on the more active beats, in which police-citizen interactions are more numerous. Some more focused observational studies have instead sampled first among officers and then, for sampled officers, among their work shifts, again observing the encounters in which those officers became involved.

Our sample was based on the sample of incidents about which we surveyed citizens, and so it was structured neither spatially nor temporally. We observed encounters that took place in any of Schenectady's eight patrol zones and on any of the three platoons. We observed many individual officers multiple times-eighteen officers at least ten times each, and one in as many as twenty-one incidents, as the primary officer. Our sample was not confined to the more active parts of the city. However, among the 1,800 incidents about which citizens were surveyed, we oversampled arrests and field interviews, on the assumption that these are the kinds of incidents in which procedural justice may be less readily practiced, and to ensure as much as possible that the subsamples would support separate analysis. ${ }^{9}$

Armchair observers need not negotiate access, as observers sometimes must do in the field when officers resist having an observer assigned to them, but officers can in effect resist observation by failing to activate the recording equipment, which we consider below in conjunction with our discussion of sample attrition. We also note here that not all of the incidents were recorded, because some of them involved foot or bicycle officers, and some transpired at the station desk. In addition, some incidents that involved the dispatch of a patrol unit did not involve a face-to-face interaction between the primary citizen, who called for assistance, and the primary officer; given our interest in the primary citizen's subjective experience, we instructed observers not to code incidents in which the officer had no interaction with the primary citizen.

Our observers coded 539 encounters from among those that we sampled and obtained recordings of from the Schenectady police. We assessed the similarities and differences among the population of incidents we sampled for observation, the sample, the set of incidents for which we obtained recordings, and the set of incidents that were coded by both observers. Few noteworthy differences appeared among comparisons including the nature of the contact (call for service, arrest, or field interview), the survey wave, the patrol area in which the incident transpired, the time of day, the nature of the incident about which callers contacted the police (as recorded in CAD records by dispatchers), features of the arrests, and the recorded race and sex of those who were arrested and field interviewed. The principal 
source of disparities between the population and the sample of incidents, on the one hand, and the incidents for which we obtained recordings and successfully coded, on the other hand, stemmed from the fact that ninety-nine of the sampled arrests took place at the police station when the arrestees turned themselves in on an arrest or bench warrant. These incidents were not captured on in-car cameras, of course, and so the incidents that we observed, compared to the incidents that we sampled, underrepresent arrests. In addition, and as a consequence, the observed incidents underrepresent incidents that took place in patrol area 1 (in which police headquarters are located), felony-level arrests, and arrests based on warrants. In all other respects, the observed incidents bear a strong resemblance to the population. Among the recordings that we received, the sources of case attrition were (1) a mismatched event (i.e., the event captured in the recording was not the sampled incident-eight cases); ${ }^{10}$ (2) the poor quality of the recording, especially the audio (seventy-five cases); (3) no detectable interaction between police and a citizen (twenty-one cases); and (4) other idiosyncratic problems (five cases).

\section{Armchair Observation: Advantages and Disadvantages}

As it has been conducted since 1966, SSO of the police places an observer in the field to see and hear directly what transpires in a police-citizen encounter. The observer accompanies the officer to whom s/he is assigned as a part of the sampling plan, and is normally able to see and hear what that officer says and does, as well as what citizens say and do to the officer. At times, when multiple officers and citizens are involved, an observer may not see or hear what other officers say or do to other citizens, whose interactions may take place in other rooms of a house, say, or in other nearby locations. But in-person observation generally affords the observer a good opportunity to hear what is said around the observed officer and also to take note of nonverbal behavior as well. The limitations stem mainly from, first, the inherent ambiguity of some elements of a police-citizen encounter, as observers map the specific words and actions of the participants into analytic categories, and second, the capacity of the observer to later recall and reconstruct the encounter, for which no replay is available, of course. The notes that observers take in the field are sparing, and the task of reconstructing the exchanges between officer and citizenor among multiple officers and/or multiple citizens-across a number of encounters observed during a full patrol shift is hard work. Since it is rare for researchers to be able to compare the observational data to other kinds of information about the same encounters, we lack evidence about the success with which observers capture the interactions in their entirety. ${ }^{11}$ And since the logistics (and costs) of in-person observation prohibit the placement of two observers in the same patrol unit, there are no (published) estimates of the inter-coder reliability of observational data.

"Armchair" observation that relies of recorded video and audio has advantages and disadvantages relative to in-person observation. One advantage is that it is 
surely much less onerous a burden for the department than in-person observation. The department's burden is borne mainly by the personnel whose duty it is to provide the recordings of sampled incidents; it was a time-consuming task in Schenectady to locate the specified incidents among the voluminous recordings, finding the right date and unit and then finding the right incident.

Another advantage concerns reactivity: the observer's presence cannot alter the behavior of the officer if the observer is not present. Inasmuch as Schenectady's police department has provided for in-car cameras since 2003, and recording is done routinely as a matter of policy and not on an episodic basis, we believe that officers have become accustomed to the fact that their interactions with citizens are captured on video and audio. ${ }^{12}$ The recordings are seldom reviewed absent exceptional circumstances, for example, to resolve a citizen complaint, and so with few exceptions, officers' recorded behavior is not subject to adverse consequences for them. ${ }^{13}$ The SPD command staff was aware that we would review a sample of incidents about which citizens had been surveyed, but so far as we can tell, patrol officers were unaware of (or at least unconcerned about) our plans for such observation; no one mentioned (or complained about) it in our interviews with patrol officers and supervisors.

Still another advantage is that the observer is not limited to the real-time event: the dynamics of the police-citizen interaction can be replayed as many times as necessary. Furthermore, resources permitting, multiple observers can code the encounter according to the same observation protocol, without having to navigate the logistical challenges of deploying two in-field observers to a sampled patrol unit. Consequently, the observers' respective judgments can be compared to one another, and their judgments on any one item can be combined, such that what one observer may miss the other observer may capture.

The disadvantages of armchair observation stem mainly from the limited field of vision that the camera affords, and this limitation is more pronounced for the dash-mounted cameras Schenectady provides than it would be for the body-worn cameras with which many departments are now outfitting their officers. For urban police, many of whose encounters with citizens-other than traffic stops-do not transpire in front of the patrol vehicle, much of what officers do is off-camera. In Schenectady, the audio was generally quite good (impaired mainly on windy days), but insofar as police-citizen interaction occurred outside the range of the camera, observers were limited to what they could hear, and so they missed nonverbal behavior. We assessed our observers' capacity to detect what transpires in the sampled police-citizen encounters in several ways:

- whether the primary citizen and/or the primary officer were visible and, whether or not they were visible, could be identified;

- the observer's estimate of how much of the audio portion of the recording was unintelligible; 
- the frequency with which observers coded items as "not determinable"; and

- how much confidence the observer felt in his/her coding.

The methodological appendix includes details of these assessments. As we discuss there, the audio proved to be of greater value than the video, and for the purposes of measuring procedural justice, which is mostly verbal behavior, we believe that armchair observation was up to the task. We also evaluated the reliability of the measures of procedural justice based on these data, which we describe below.

\section{PROCEDURAL JUSTICE IN SCHENECTADY POLICE ACTION}

We observed 539 police-citizen encounters drawn from among the 1,800 about which citizens had been interviewed. Arrests and field interviews are somewhat overrepresented in our observed encounters, based on the premise that such incidents represent, on average, somewhat more challenging dynamics for officers to manage; overall results are weighted to represent the entire population of contacts during this time period.

Using the four domains of procedural justice as a guide to actions that signify procedural (in)justice, we will first describe the actions of Schenectady police in each of four domains, but we thereupon combine those domains for analytical purposes, as Jonathan-Zamir et al. (2015) did. However, unlike Jonathan-Zamir and her colleagues, we distinguish behaviors that are procedurally just from behaviors that are procedurally unjust, forming two distinct measures of the procedural justice with which police act. Officers may take only procedurally just actions in their interactions with citizens, only procedurally unjust actions, or both (or neither) just and unjust actions, in any of the domains of procedural justice. Moreover, there is good reason to suspect that procedurally unjust actions have a greater (negative) effect on citizens' subjective experience than procedurally just actions have a (positive) effect, as we discussed in chapter 3. So we believe that it is useful to separate the just and the unjust and specify two behavioral constructs: procedurally just action, and procedurally unjust action.

We exclude from measures of procedurally (un)just action those forms of behavior whose theoretical status is ambiguous, such as the overt use of police authority-conducting searches or frisks, using physical force, or even issuing commands. We agree with Jonathan-Zamir et al., who "regard force as an inappropriate indicator of dignity or any other procedural justice element. Force is an action that may aggravate or provoke a citizen, but the character of the social status that it signals to those at the scene is not inherently clear simply by knowing that some degree of coercion was applied" $(2015,856)$. Commands can be issued 
rudely or disrespectfully, of course, but the rudeness or disrespect is captured in the measures of the quality of treatment. ${ }^{14}$ We do not exclude any of these actions from our analysis, hence we take them up below.

We also exclude from measures of procedural justice features of the context of police-citizen interactions, though we describe and include contextual characteristics that may be relevant in our analysis. For example, the evidence of criminal wrongdoing, especially when it is sufficient to constitute probable cause for arrest, may be important in shaping a citizen's interpretation of police actions, but is not intrinsic to the action. Another feature of context is how the encounter begins: at the initiative of police, acting on their own authority, or at the behest of a citizen who requested police assistance-a difference that turns partly on the actions of a party other than the police.

Below we examine the frequency with which actions are taken in each of the domains of procedural justice, forming in each of the four domains a subscale of just action and a subscale of unjust action by summing across the coded actions in that domain. Then we form indices of procedural justice and procedural injustice by summing the respective subscale scores, and describe the distributions of scores along each construct. We focus mainly though not exclusively on the "primary citizen" - the citizen whom we interviewed, and whose subjective experiences we will examine in the next chapter. Furthermore, we examine only the 411 cases in which both observers were able to identify the primary citizen, and so we exclude 59 cases in which only one of the two observers was able to identify the primary citizen, and an additional 63 cases in which neither observer was able to identify the primary citizen. ${ }^{15}$

The primary citizen might interact only with the primary officer, that is, the officer whose unit was dispatched to a call for service, or whose name appeared on an arrest report or field interview card; the primary officer was in most instances the lead officer. We form a procedural justice scale and a procedural injustice scale for the actions of the primary officer toward the primary citizen in each encounter, averaging the two coders' scores. Other officers were present and interacted with the primary citizen in 90 of the 411 encounters, and, as we show below, these officers tended to serve as backup, but primary citizens could also interact with officers other than the primary officer. Thus we also form corresponding scales of procedural justice and procedural injustice for other officers' actions toward the primary citizen. Finally, inasmuch as officers' actions toward other citizens in the encounter could influence the subjective experience of the primary citizen, we also construct scales for police actions toward other citizens.

We formed the subscales and the scales for each of the two observers for each encounter, and then formed subscales and scales for the encounter by averaging the individual observers' scores. We assessed the level of inter-coder agreement in terms of the interclass correlations, which we report below in connection with 
each of the scales. ${ }^{16}$ When agreement was less than perfect, the averaged scale scores are not integers.

\section{Voice/Participation}

Citizens want to have an opportunity to explain themselves and their circumstances to police-to tell their side of the story, and to participate in decision-making even if they cannot determine the outcome. Hence police are procedurally just when officers ask citizens to tell them what happened, to explain their actions, or to explain what they want the police to do. Police are procedurally just also when they listen to citizens and pay attention to them, and when they indicate that they are considering the citizen's views. Observers characterized overall how well the officer listened to the citizen on a scale from o to 5, and they also characterized the extent to which the officer considered the citizen's view on a similar scale; scores of 4 and 5 on those scales were treated as procedurally just.

Furthermore, when officers make requests of citizens, or offer suggestions, or even try to persuade or negotiate, they are allowing citizens to make choices and in this way to participate in the decision-making, so we treat such actions by police as forms of procedurally just treatment. For example, an officer might ask a citizen to stop his/her disorderly or illegal behavior. Or an officer might try to persuade a citizen to leave the scene. (In previous research that was concerned with citizens' compliance with police requests, such requests were a defining feature of the encounters and so could not be treated as a component of procedural justice.)

When these actions are combined to form a scale, the scores range from o to 8 , and the intraclass correlation of the scale is 0.54 . The actions that contribute to these scores especially include officers paying attention to what citizens had to say, asking citizens what happened, listening (at least 4 on a $0-5$ listening scale), and considering citizens' views ( $4-5$ on a $0-5$ scale) ${ }^{17}$ Across all of the contacts, the mean score is 3.43 , as shown in table 3 , with somewhat higher mean scores in encounters in which the citizen had called for police assistance and somewhat lower scores in encounters in which the citizen had been stopped or arrested. Even so, the scores for the different types of contact are not widely disparate.

By contrast, police are procedurally unjust when the officer does not pay attention to what the citizen had to say, does not listen, and does not consider the citizen's views. We also treat as procedurally unjust instances in which the officer interrupted the citizen. When these actions are combined to form a scale, the scores range from o to 4 , and the intraclass correlation of the scale is 0.64 . The most frequently observed actions were the officers interrupting citizens, not considering the citizens' views (below 2 on a $0-5$ considered views scale), and not paying attention to what citizens had to say. Officers were seldom observed to act in any of these ways, however, though it was more common among encounters in which the citizen was arrested than in either calls for service or stops, as shown in table 3. 
TABLE 3 Scales of Procedural Justice and Procedural Injustice in Action

\begin{tabular}{lrrccc}
\hline & Range & All contacts* & Calls & Arrests & FIs \\
\hline Just: voice & $0-8$ & $3.43(1.42)$ & $3.64(1.38)$ & $2.76(1.39)$ & $2.69(1.24)$ \\
Just: quality of treatment & $0-3.5$ & $0.56(0.72)$ & $0.55(0.68)$ & $0.57(0.82)$ & $0.57(0.83)$ \\
Just: neutrality & $0-3.5$ & $0.92(0.76)$ & $0.85(0.70)$ & $1.29(0.91)$ & $0.89(0.85)$ \\
Just: trustworthy motives & $0-6.5$ & $2.08(1.20)$ & $2.25(1.18)$ & $1.69(1.19)$ & $1.04(0.72)$ \\
Procedurally just action & $0-15$ & $6.99(2.96)$ & $7.30(2.81)$ & $6.30(3.30)$ & $5.19(2.88)$ \\
& & & & & \\
Unjust: voice & $0-4$ & $0.33(0.56)$ & $0.26(0.48)$ & $0.67(0.79)$ & $0.26(0.41)$ \\
Unjust: quality of treatment & $0-6.5$ & $0.23(0.73)$ & $0.15(0.54)$ & $0.51(1.10)$ & $0.50(1.20)$ \\
Unjust: neutrality & $0-1$ & $0.03(0.14)$ & $0.02(0.12)$ & $0.06(0.19)$ & $0.07(0.18)$ \\
Unjust: trustworthy motives & $0-2.5$ & $0.09(0.29)$ & $0.07(0.28)$ & $0.17(0.35)$ & $0.01(0.08)$ \\
Procedurally unjust action & $0-12.5$ & $0.68(1.35)$ & $0.51(1.09)$ & $1.41(2.06)$ & $0.85(1.48)$ \\
\hline
\end{tabular}

${ }^{\star}$ Weighted results

\section{Quality of Treatment}

Citizens want to be treated with dignity and respect, and such treatment can take several forms. If officers greet citizens at the outset of their encounter, they can do so in ways that signal respect-for example, by using generically formal terms, such as "sir" or "ma'am," or if the officer knows the citizen's name, addressing him or her as Mr. or Ms. ---, or using the citizen's first name. Similar considerations apply when the officer and citizen part ways at the end of the encounter. Furthermore, officers can through a friendly "manner" signal that the status disparity that stems from police authority need not be observed. We also consider as respectful treatment officers' use of polite terms, such as "please" and "thank you."

When these actions are combined to form a scale, the scores range from o to 3.5, and the intraclass correlation of the scale is 0.61 . The most frequent such action is use of polite terms (e.g., "please" and "thank you"), followed by a friendly manner. We seldom observed these actions in any type of police-citizen contact, though, and the scores on this scale are very similar across types of contacts, as shown in table 3 , above.

Officers' treatment of citizens is procedurally unjust when officers greet or leave citizens in an insulting way (with name-calling abuse, for example), when officers' "manner" is hostile, when the officer makes derogatory remarks or is otherwise disrespectful to the citizen, and when officers act in a patronizing, sarcastic, or angry way toward citizens. When these actions are combined to form a scale, the scores range from o to 6.5 , and the intraclass correlation of the scale is 0.80 .

\section{Neutrality}

Citizens believe that decisions are made fairly when they see evidence that decision-makers have considered objective facts and are evenhanded in their 
treatment of the parties involved. That does not imply slavish equality of treatment, as Jonathan-Zamir et al. (2015) point out. One way that citizens can infer that police are basing their judgments on facts, and not on prejudices or biases, is in hearing officers explain their actions and decisions. ${ }^{18}$ This can take several forms. An officer might explain to the citizen how the officer's resolution is based on legal standards or requirements, or how it is that the officer is giving the citizen a "break," with less punitive action than the law allows. Or the officer could explain, in response to a specific citizen request, why the officer cannot or will not oblige the request. Or an officer might explain to the citizen why s/he is conducting a search or frisk. Lest we fail to take account of the myriad other explanations that an officer might provide to a citizen, observers also characterized more generally how well the officer explained the reasons for the officer's decisions or actions to the citizen, on a scale from o to 5; scores of 4 and 5 were treated as procedurally just. ${ }^{19}$ When these actions are combined to form a scale, the scores range from o to 3.5, and the intraclass correlation of the scale is 0.59 . The scores on this scale are fairly low overall, but they are higher in arrests and stops than in calls for service, as shown in table 3 above. Indeed, an explanation of some kind(s) is modal in arrests and stops.

We rely on observers' characterizations of how well the officer explained his/her reasons for decisions and actions to the citizen, treating as procedurally unjust a score of o or 1 on the $0-5$ continuum. Such low scores were infrequent. In thirty-four encounters one but not both of the coders placed the officer's actions in this respect at the low end of the continuum, and in five encounters both coders agreed on such a characterization. It was somewhat more common in arrests. The measure that we form, then, ranges only from o to 1 , and the intraclass correlation of the scale is 0.38 .

\section{Trustworthy Motives}

Citizens perceive that decisions are fair when they believe that authorities care about their well-being and are taking their needs into account. Police can exhibit such care and concern in several ways. An officer can comfort a citizen, promise to give the citizen's situation special attention, tell or ask the citizen to call if the citizen's problem recurs, or-at the officer's initiative-provide information or physical assistance, or contact an agency for assistance on the citizen's behalf. An officer also exhibits care and concern in fulfilling (or promising to fulfill) citizen's requests, for example, to file a report, to provide information, or to have another citizen leave the scene. We also treat patience as an outward sign of such concern; observers characterized officers' impatience with the citizen on a scale of o to 5 , and we treat scores of $o$ and 1 as procedurally just patience. When these actions are combined to form a scale, the scores range from o to 6.5, and the intraclass correlation of the scale is 0.73 . Some such action was nearly ubiquitous in calls for service and modal in arrests and stops, as shown in table 3. 
When officers ignore citizens' requests, or refuse to fulfill them without explanation, they do not exhibit trustworthy motives, leaving citizens to draw unfavorable inferences about the fairness of police decisions. When an officer tells a citizen not to call police if the problem recurs in the future, s/he may be taken to imply a disregard for the citizen's concerns, as the officer does when s/he is impatient. When these actions are combined to form a scale, the scores range from o to 2.5, and the intraclass correlation of the scale is 0.58 . These actions were seldom observed in any of the types of contacts, as shown in table 3.

\section{Scales of Procedural Justice and Injustice in Action}

Like Jonathan-Zamir et al. (2015), we are persuaded that formative measures of procedural (in)justice are more compatible with the situationally contingent nature of police work, in the context of which only some but not other types of actions fit the circumstances. In order to capture the levels of procedural justice and procedural injustice that officers' actions represent, respectively, we map the coded actions onto the two conceptual constructs, and arithmetically sum across the actions in each category.

The scale of procedurally just action, which is formed by summing across the procedurally just subscales, ranges from o to 15 with a mean of 6.99, and it has an intraclass correlation of 0.73 . This overall scale exhibits correlations with individual subscales ranging from 0.50 to 0.85 , respectively, with a mean correlation of 0.67 . The scale of procedurally unjust action formed by summing across the procedurally unjust subscales ranges from o to 12.5 with a mean of only 0.68 , and it has an intraclass correlation of 0.80 . This overall scale exhibits correlations with individual subscales ranging from 0.4 to 0.86 , respectively, with a mean correlation of 0.70. Table 3 displays the scale means and standard deviations for the contacts as a whole and for each type of contact: calls for service; arrests; and field interviews.

The correlation between the two scales is, as expected, negative and of moderate magnitude: -0.26. Scale scores are for the most part jointly concentrated in moderate-to-high procedurally just categories and none to low procedurally unjust categories, with two-thirds of the cases in these four cells of a cross-tabulation.

\section{Other Officers' Actions}

The primary citizen interacted with an officer other than the primary officer in ninety encounters, and so we should take account of those officers' behavior in order to describe and understand the procedural justice that citizens experience. Both scales' scores tend to be low, because other officers served as backup and thus seldom took action. In the ninety encounters in which other officers were present and interacted with the primary citizen, the mean score for other officers' procedurally just action was 4.33 , and the mean score for procedurally unjust action was 0.72 . 


\section{Action toward Other Citizens}

Police took action toward citizens other than the primary citizen in 60 percent of the encounters, and of course these actions could affect the subjective experience of the primary citizen. However, we would expect that the impact of police behavior-just or unjust-toward other citizens would be weaker than that of actions directed toward the primary citizen, and depending on the relationship of the primary citizen to the other citizen(s), even procedurally unjust action toward other citizens might not be unfavorably received by the primary citizen. The mean of procedurally just action toward other citizens was 4.49, while the mean of procedurally unjust action was 0.72 .

\section{OTHER POLICE ACTIONS IN SCHENECTADY}

How police use their authority matters, but we might also expect that whether police use any of a variety of forms of authority matters as well. Officers may issue commands or warnings, use physical force, pat citizens down or conduct full-scale searches of citizens' persons or vehicles, whether or not they are procedurally just or unjust.

Verbal "force" is one form of police authority, and the form that, as previous research shows, is the most commonly exercised. Here we treat as verbal force any occasion on which one or more of the officers: commanded or explicitly threatened a citizen to leave the scene, cease disorderly or illegal behavior, or provide information; threatened to charge or cite the citizen, notify another agency, or to use physical force. Physical force encompasses the use of physical restraints (exclusive of handcuffing), the use of pain-compliance techniques, or the use of impact force. (No firearm discharges were observed.) Searches or frisks/pat-downs of persons were treated as a single category, as were searches of vehicles.

Verbal force was seldom used toward the primary citizen in the context of encounters prompted by the citizen's call for police assistance (3.2 percent), as one would expect, and other forms of authority were rarely exercised in those instances-physical force in just 0.8 percent, and a search or frisk in 0.4 percent. In arrests and field interviews, however, each of these actions was much more common. Verbal force was used in nearly half of the arrests and more than one-fifth of the field interviews, physical force in slightly more than one-third of the arrests and one in seven field interviews, and a search or frisk was observed in nearly half of the arrests (not all of which were custodial) and 30 percent of the field interviews.

All of these actions are associated with procedural justice and injustice. In encounters involving verbal or physical force, the procedural justice scale score is 1 to 2 points lower than in encounters with no force, and the procedural injustice scale averages about 2.5 (compared to 0.5 in other encounters). In encounters in which officers conducted a search, the procedural justice scale score is 1 point lower than 
in encounters with no search, and the procedural injustice scale averages about 1.5 to 1.7 (compared to 0.6 in other encounters).

We did not ask observers to make judgments about the legality of searches or the reasonableness of officers' use of physical force; the practice of systematic social observation has prompted observers only for concrete description and not for legal opinions that they are not trained to make. Neither did we ask lawyers to make these assessments (see, e.g., Gould and Mastrofski 2004), and if we had, we might have found that it is illegal searches and unreasonable force that are associated with procedural justice and injustice. But some recent evidence-the only empirical evidence on the question-indicates that citizens' assessments of the propriety of police behavior are not based on officers' compliance with the technical requirements of Constitutional law, but rather on citizens' perceptions of procedural justice (Meares et al. 2012). We return to this issue when we reexamine citizens' subjective experience in chapter 7 .

\section{THE CONTEXT OF POLICE ACTION}

More than three-quarters ( 78 percent) of the field interviews (FIs) and almost half (44 percent) of the arrests were police-initiated encounters. Citizen-initiated incidents could have been initiated by the primary citizen or by another citizen. The highest levels of procedural justice, on average, and lowest levels of procedural injustice were observed in calls for service. Among FIs and arrests, the procedural justice with which officers acted was somewhat greater in police-initiated encounters than in citizen-initiated encounters, perhaps because police-initiated encounters call for some explanation of officers' interventions. The procedural injustice with which officers acted was also somewhat greater in police-initiated arrests and FIs.

Officers' procedural justice and injustice varies some across different types of problems. Both procedural justice and procedural injustice are highest in encounters that concerned violent crime, and also fairly high in interpersonal conflicts. Procedural justice was lowest in encounters that involved suspicious circumstances.

Based on the observations (and hence exclusive of information contained in police records), and following the practice of previous observational research established in the mid-1990s (Mastrofski, Worden, and Snipes 1995), we formed a scale of legal evidence of criminal wrongdoing by the primary citizen. The scale is a weighted combination of several pieces of coded information: whether the officer observed the citizen commit an offense; whether there was physical evidence implicating the citizen; whether the citizen gave a full confession to an offense; whether the officer heard eyewitness testimony implicating the citizen; and whether the citizen gave a partial confession. Assigning two legal "points" to each of the first three factors and one point to each of the last two factors, the evidence 
scale can range from o to 8 ; in general, and somewhat loosely, we could consider scores of 2 and above to represent probable cause for arrest. In the encounters that we observed in Schenectady, the scale ranges from o to 5. Procedural justice declines and procedural injustice increases with increasing evidence between o and 3 on this scale, though this simple association could be driven by the citizen's role in the encounter (as, e.g., suspect or complainant); this pattern reverses at the higher levels of evidence, though the numbers of cases become rather small.

Part of the context for police action is whether and how citizens resist or challenge officers' authority or display disrespect toward police. Resistance can take different forms: passive resistance, by refusing or ignoring officers' questions or commands; defensive resistance, by fleeing or trying to evade officers' grasp; and aggressive resistance, by attacking or threatening to assault officers. Resistance in any of these forms was very infrequent in the Schenectady sample of encounters, and it was with rare exceptions limited to arrests and field interviews. Among arrests, observers recorded passive resistance by the primary citizen in 17 percent (i.e., twenty-two encounters), defensive resistance in 7 percent, and aggressive resistance in only two cases. Disrespect was more common, observed in 12 percent of the encounters, including 8 percent of the calls for service, more than one-quarter of the arrests, and one-sixth of the field interviews. Disrespect can consist of derogatory comments about police and/or any of a variety of actions that would be widely interpreted as disrespectful in any social setting. ${ }^{20}$ Multiple forms of resistance can occur in the same encounter, of course, and resistance can overlap with disrespect, but 78 percent of the occasions of citizen disrespect were not observed in conjunction with citizen resistance of any detected kind. Overall, neither resistance nor disrespect was observed in 86 percent of the encounters.

The demeanor of a suspect has been a consistent predictor of police action in previous studies-officers respond punitively to those who show a disregard for their authority and thereby flunk the "attitude test." This has remained true despite a debate among researchers regarding the appropriate definition and operationalization of "demeanor." David Klinger (1994) first questioned the measurement of demeanor in previous research, arguing that prior studies had failed to adequately isolate and control for crime committed by suspects during their encounter with police (in particular, crime against the police). Although subsequent research found that the original findings regarding the influence of demeanor hold (e.g., Lundman 1994, 1996; Worden and Shepard 1996; Klinger 1995, 1996; Worden et al. 1996), Klinger's critique pushed research to exercise greater care in the conceptualization and measurement of demeanor (and its separation from suspect resistance). However, despite all of the research conducted to date, the demeanor/ resistance question has still not been conclusively answered. That officers react to negative behavior on the behalf of a citizen is not in dispute. The forms that such behavior takes, however, and the ways in which officers interpret representations 
of "attitude," remain open questions if we approach police behavior as the outcome of a decision-making process. Although some forms of resistance (e.g., passive) are legal, officers may not make such a distinction in the field. It may be that officers view both disrespect and forms of resistance as equal affronts to their authority.

Resistance and disrespect are associated with the procedural justice and especially injustice with which officers act. Procedural justice is somewhat lower (less than 1 point lower on the scale) when citizens are disrespectful, and all three forms of resistance are associated with still lower levels of procedural justice. But it is procedural injustice that is more strongly associated with resistance and disrespect. Whether resistance or disrespect are cause or effect-a feature of the situation to which officers respond or a response by citizens to officers' behavior-is a question that cannot be entirely resolved by these data, but we can at least partially disentangle the citizens' disrespect toward the police and officers' disrespect toward citizens. Citizen disrespect followed police disrespect of the citizen in seven of sixty-one (unweighted) cases of citizen disrespect toward police; citizen disrespect was reciprocated by police in sixteen and not reciprocated in the remaining thirty-eight encounters. In sixteen other (unweighted) cases, police disrespected the citizen and the citizen did not reciprocate. In seventy-seven encounters in which one or both parties disrespected the other, police initiated the disrespect in twenty-three, or about 30 percent of the time. From these data we can infer with some confidence that more often than not, citizen disrespect is a context for officers' behavior and not an effect of officers' disrespect.

Another facet of the context for police action is the condition of the citizen with whom officers interact. We might expect that officers' behavior would be affected by elements of the citizen's capacity to communicate and act rationally, and so citizens who exhibit signs of mental disorder or intoxication might be treated differently. Mental disorder was infrequent, observed in only eight encounters, in five of which the citizens were arrested. Intoxication was a condition observed somewhat more frequently, in just under 8 percent of all contacts, but was fairly prevalent among arrests, as more than one quarter of the primary citizens in arrest encounters exhibited mild (15 percent) or strong (12 percent) intoxication. The procedural justice with which police act does not appear to be strongly associated with any of these conditions, with scale scores averaging 6.2-6.4, but the procedural injustice with which police act is considerably greater under each of these circumstances, with scale scores of 1.6 to 2.3 , than when citizens exhibit none of these conditions (an average scale score of 0.6 ).

\section{TALES FROM THE FIELD}

The virtue of quantitative analysis is in breaking police-citizen interactions into discrete pieces so that they can be carefully examined, piece by piece, but a sense 
of the texture of behavior and interpersonal dynamics can be compromised by such fragmentation. It might be instructive, therefore, to consider some examples of the police-citizen encounters that we have analyzed above. For some of the observed encounters, an observer prepared a narrative description of the event; we draw on those narratives here. In each case, the primary officer appears as "O1," and other officers as " $\mathrm{O}_{2}$," " $\mathrm{O}_{3}$," while citizens are " $\mathrm{C}_{1}$," " $\mathrm{C}_{2}$," and so on.

In one incident (case 6-1, below), police responded to a 'keep the peace' call shortly after 5 p.m. A landlord had called on behalf of one of his tenants, who had a guest stay past his welcome; but under state law, the guest had stayed long enough to claim the apartment as his legal residence. The officer listened to the tenant's explanation of the situation, asked some clarifying questions, and explained that under the circumstances, the police could not take legal action. The officer also expressed his sympathy for the tenant's predicament, and offered some advice about how not to make the situation worse. The entire encounter took only six minutes, but in that space of time, the officer's actions manifested each element of procedural justice: he gave the citizen voice in explaining the situation; he sought additional information, so that his decision about how to proceed would be based on facts; he expressed concern for the citizens' needs and well-being; and he treated the citizens with dignity and respect. The score on the procedural justice scale was 13; the procedural injustice score was zero.

CASE 6-1

O1 was initially greeted by $\mathrm{C} 1$ (male) on the sidewalk of a residential neighborhood. After $\mathrm{O}_{1}$ asked who called, $\mathrm{C}_{1}$ identified himself as the landlord and $\mathrm{C}_{2}$ (male) as his tenant. $\mathrm{C}_{1}$ explained that a friend of $\mathrm{C}_{2}$ and $\mathrm{C}_{2}$ 's wife had recently moved in, despite not being on the lease. $\mathrm{O}_{1}$ inquired about the location of this person, and $\mathrm{C}_{1}$ says he is off scene.

$\mathrm{C}_{1}$ stated that his tenants wish for this person to leave. O1 asked $\mathrm{C}_{2}$ exactly how long their friend has lived there, as that is the main issue. After $\mathrm{C}_{2}$ stated his friend has lived there for "about a month," O1 respectfully described to both citizens that $\mathrm{C}_{2}$ 's friend legally lives in the residence, and $\mathrm{C}_{1}$ must have him legally evicted. O1 explained that under different circumstances (if the "friend" did not have proof of residence) he could provide assistance in getting him to leave the property.

It is evident that $\mathrm{O}_{1}$ understands it is an unfair situation, and he expressed this understanding to the citizens. O1 explained that despite the fact the "friend" is not paying rent or helping $\mathrm{C}_{2}$ and $\mathrm{C}_{2}$ 's wife, he is unable to help due to NYS law.

O1 advised the citizens to avoid the "friend" in the meantime in order to not turn the situation into a domestic dispute. O1 also advised $\mathrm{C}_{2}$ to respect the clause in the lease agreement that states no one may live with them in order to avoid the current situation. Before leaving O1 suggested that the citizens call the police when the "friend" returns so the police may talk to him, but they must start the eviction process in order to make him leave. 
In another case (6-2), an officer is called to a convenience store at nearly 11 p.m., where he encounters a man in a strongly inebriated state:

CASE $6-2$

$\mathrm{O} 1$ arrived at a convenience store and parked before walking toward the back of the building. O1 greeted C1 (male) by asking him, "What's up?" C1 was noticeably intoxicated, and told $\mathrm{O}_{1}$ he was tired. $\mathrm{O}_{1}$ then asked $\mathrm{C}_{1}$ where he lived, and $\mathrm{C}_{1}$ asked him if he was a cop, to which the officer responded that he was indeed a cop. C1 then gave $\mathrm{O}_{1}$ his address, and $\mathrm{O}_{1}$ asked what he was doing at the convenience store; $\mathrm{C}_{1}$ 's response was inaudible. $\mathrm{O} 1$ then asked $\mathrm{C}_{1}$ who he lived with, and $\mathrm{C} 1$ said he lived with his cousins and his mother. $\mathrm{O}_{1}$ then asked why $\mathrm{C}_{1}$ was drinking, and $\mathrm{C}_{1}$ said he had "a lot of problems on his mind." C1 then began to tell O1 that "God told me it is better to be truthful," and O1 patiently let $\mathrm{C}_{1}$ talk. $\mathrm{C}_{1}$ then told $\mathrm{O}_{1}$ he would be truthful with him, so $\mathrm{O}_{1}$ asked what $\mathrm{C}_{1}$ would be truthful about, but $\mathrm{C}_{1}$ said he did not know. $\mathrm{C}_{1}$ then repeatedly asked $\mathrm{O}_{1}$ if he had a problem, and $\mathrm{O}_{1}$ simply said, "No." O1 then asked $\mathrm{C}_{1}$ how long he had been at the convenience store, and $\mathrm{C}_{1}$ said he thought he had been there for about an hour. O1 then asked $\mathrm{C}_{1}$ if he knew what time it was, and after $\mathrm{C}_{1}$ said he did not know, $\mathrm{O}_{1}$ told him to guess. $\mathrm{C}_{1}$ then asked the officer if it was morning (it was in fact 22:59). O1 said no, and told $\mathrm{C}_{1}$ the time. $\mathrm{O} 1$ then pointed out to $\mathrm{C}_{1}$ that he had an open container of alcohol, and asked $\mathrm{C} 1$ if he had ever gotten an open container ticket. $\mathrm{C}_{1}$ said no before standing up to retrieve his ID. C1 spoke unintelligibly for a few minutes while O1 examined his ID.

After several minutes $\mathrm{C}_{1}$ asked the cop if he had a warrant, and $\mathrm{O}_{1}$ told him that's what he was waiting to find out. O1 also told him he was there because people had called and $\mathrm{C}_{1}$ was making people nervous. $\mathrm{O}_{1}$ suddenly asked if something that $\mathrm{C}_{1}$ had in his possession was cologne or pills. $\mathrm{C}_{1}$ ignored the question and again asked if he had any warrants. $\mathrm{O}_{1}$ told $\mathrm{C}_{1}$ he did not have any warrants, and asked twice more if $\mathrm{C}_{1}$ was holding pills or cologne. $\mathrm{C}_{1}$ spoke unintelligibly while handing the item to $\mathrm{O}_{1}$, who determined it was cologne. $\mathrm{O}_{1}$ told $\mathrm{C}_{1}$ to wait where he was while he returned to his car.

After a few minutes $\mathrm{O}_{1}$ asked $\mathrm{C}_{1}$ if there was anything left in the alcohol container. $\mathrm{O}_{1}$ asked multiple times before $\mathrm{C}_{1}$ said it was empty. O1 then asked $\mathrm{C}_{1}$ if he was supposed to be at the convenience store, and $\mathrm{C}_{1}$ said he did not know. O1 told him he was not allowed to be at the convenience store due to prior incidents. O1 proceeded to write $\mathrm{C}_{1}$ a ticket, and asked him various questions such as name, date of birth, etc. while doing so. When asked how old he was, $\mathrm{C} 1$ told the officer he was older than him. When O1 asked again, $\mathrm{C}_{1}$ replied by asking the officer, "How old do you want me to be?" O1 asked him why he was making the information gathering process so difficult, and warned $\mathrm{C}_{1}$ that he could take him to the station. $\mathrm{C}_{1}$ asked $\mathrm{O}_{1}$ where his car was, and $\mathrm{O}_{1}$ pointed to his car and said with a light tone, "That one, with the big dog in the back. It will bite your ass." O1 then told C1 he had to take down C1's information and then he could send him on his way. $\mathrm{C}_{1}$ then asked $\mathrm{O}_{1}$ if he liked him, and $\mathrm{O} 1$ told him "So far, yeah." O1 lightly joked about C1 being "a little difficult." $\mathrm{C}_{1}$ did not give O1 much trouble for the remainder of the questions. Any lack of attention exhibited by $\mathrm{C} 1$ during O1's questions could be attributed to his inebriated state. 
O1 returned to his car to complete paperwork and returned to $\mathrm{C} 1$ with a ticket and told him he had a court date the next Monday. O1 told $\mathrm{C}_{1}$ he was not supposed to be at the convenience store, and he needed to think about being "passed out and intoxicated." C1 repeatedly told O1 he was "supposed to be his friend."

O1 stayed for a few minutes after giving $\mathrm{C}_{1}$ his ticket to make sure he took his keys and his bike. O1 reminded $\mathrm{C}_{1}$ of his court date and that he was not allowed at the convenience store before leaving.

The officer is clearly very patient with the man, shows concern for his welfare, treats him with respect, and explains why he is there, what he is doing and why. The procedural justice scale score was 8.5; procedural injustice registered 2.5 on the scale.

Less procedural justice, and greater procedural injustice, can be seen in case $6-3$, as officers responded to a call for service in the late afternoon:

CASE $6-3$

$\mathrm{O}_{1}$ and $\mathrm{O}_{2}$ stopped on a residential street in front of a house with four citizens standing outside on the sidewalk. $\mathrm{O}_{1}$ and $\mathrm{O}_{2}$ approached the citizens on the sidewalk and $\mathrm{O} 1$ asked which of the citizens called. $\mathrm{C} 1$ (male) told the officer he called because $\mathrm{C}_{2}$ (male) had insulted him and a dispute had developed. As $\mathrm{C}_{1}$ explained, $\mathrm{O}_{1}$ then asked for the citizens to make a long story short and explain why the police were contacted. $\mathrm{C}_{2}$ told the officers that $\mathrm{C}_{1}$ had held a knife to him. O1 asked what he wanted the police to do and $\mathrm{C}_{2}$ told the officers he wanted $\mathrm{C}_{1}$ to leave. As $\mathrm{C}_{1}$ was standing in the doorway of the house, $\mathrm{O}_{1}$ assumed he lived there and told $\mathrm{C}_{2}$ he could not make him leave. $\mathrm{C}_{2}$ then told the officer $\mathrm{C}_{1}$ was not on the lease, and $\mathrm{O}_{1}$ replied by telling him if he has been there for thirty days he must be evicted. $\mathrm{C}_{2}$ attempted to tell the officers that $\mathrm{C}_{1}$ had not been there for thirty days. $\mathrm{O}_{2}$ did not believe this, as he had been to the same address two months earlier and knew that $\mathrm{C}_{1}$ had been there for at least thirty days. $\mathrm{O} 1$ turned to $\mathrm{C}_{1}$ and asked how long he had lived there, and $\mathrm{C}_{1}$ said he had been there for five months. Upon hearing this $\mathrm{C}_{2}$ began to argue with C1. As they were arguing, $\mathrm{O}_{1}$ said $\mathrm{C}_{1}$ must be evicted if $\mathrm{C}_{2}$ wanted him out of the residence. $\mathrm{C}_{1}$ then said that $\mathrm{C}_{2}$ had forced his way in and had put his hands on $\mathrm{C}_{1}$ 's neck. After a brief moment of arguing between the citizens, $\mathrm{O}_{1}$ announced that he and $\mathrm{O}_{2}$ were going to leave, and $\mathrm{C}_{2}$ needed to have $\mathrm{C}_{1}$ evicted. $\mathrm{C}_{1}$ then said, "That guy [C2] attacked me and you're just going to leave?" O1 simply said, "Yeah." After a few moments of complaining by both citizens $\mathrm{O}_{1}$ told them to "cry about it." The citizens continued to argue with the officers about not honoring their complaints, and $\mathrm{O}_{2}$ told them the officers must honor either both or neither complaints. Both officers left without any parting remarks.

The conflict between the citizens clearly makes the situation an emotional and perhaps volatile one. The officers showed little interest in learning about the situation or concern about either citizen's well-being, however. One citizen claimed to be the victim of an armed assault, but the officers seemed quick to seize upon a definition of the situation that called for no police action, and even mocked the 
citizens' disgruntlement with the limited police response. The procedural justice scale score was 4.5; procedural injustice scored 7.0.

Finally, case 6-4 illustrates what observers captured as (predominantly) procedural injustice by police in the context of citizen resistance and disrespect, likely owing at least partly to inebriation. In a 45-minute encounter that began just after midnight:

CASE 6-4

$\mathrm{O}_{1}$ and $\mathrm{O}_{2}$ were driving through downtown and responded to a call at a bar. $\mathrm{O}_{1}$ and $\mathrm{O}_{2}$ approached $\mathrm{C}_{1}$ (male) on the sidewalk who was arguing with someone inside the bar. There were also approximately four other citizens standing outside around $\mathrm{C}$. C1 told the officers as they approached that a person in the bar had choked him and thrown him on the floor. $\mathrm{C} 1$ alleged that he was thrown out because his friend had thrown up inside the bar. C1 told the officers he had hurt his arm during the incident, and that the person involved with him in the incident tried to fight him. C1 told the officers his friend had a video of the encounter on his phone and that he wanted to press charges against the bar. At this point $\mathrm{C}_{1}$ was very agitated and began to argue with $\mathrm{O}_{1}$ and $\mathrm{O}_{2}$ as they told him he needed to calm down and listen. O1 asked $\mathrm{C}_{1}$ for his name, and $\mathrm{C} 1$ told him his name before continuing to shout about previous incidents he had at the bar. $\mathrm{C} 1$ was not responding to the officer's requests to calm down and lower his voice, and after repeated requests by the officers, C1 quickly said he was sorry before continuing to yell. O1 said he did not believe he was sorry and told him to shut his mouth. $\mathrm{O}_{1}$ told $\mathrm{C}_{1}$ he had lost his talking privileges, and $\mathrm{C}_{2}$ (male) told the officers he wanted to ask them a question. $\mathrm{O}_{1}$ asked $\mathrm{C}_{1}$ and $\mathrm{C}_{2}$ if they wanted to do jail time before both officers walked inside the bar while $\mathrm{C}_{1}$ and his friends stayed on the sidewalk.

Inside the bar $\mathrm{O}_{1}$ asked $\mathrm{C}_{3}$ if he worked there, and $\mathrm{C}_{3}$ (male) said he was the bartender. $\mathrm{O}_{1}$ asked $\mathrm{C}_{3}$ what happened, and $\mathrm{C}_{3}$ told him $\mathrm{C}_{1}$ was in the bar with a friend, and the friend was falling asleep. $\mathrm{C}_{3}$ had told $\mathrm{C}_{1}$ 's friend to either get up or leave, and he threw up two minutes later. $\mathrm{C}_{3}$ had then told $\mathrm{C}_{1}$ and the group $\mathrm{C}_{1}$ was with they had to leave. $\mathrm{C} 1$ refused to leave, so the doorman put him in an armlock and pushed him out the door.

The officers returned to the sidewalk and $\mathrm{O}_{1}$ asked $\mathrm{C}_{1}$ and $\mathrm{C}_{2}$ if they had been asked to leave. $\mathrm{C}_{2}$ then said, "This is the United States of America, I don't have freedom of speech?" O1 again asked $\mathrm{C}_{1}$ and $\mathrm{C}_{2}$ if they had been asked to leave, to which $\mathrm{C}_{2}$ said yes, but for the wrong reasons, and $\mathrm{C}_{1}$ said he still wanted to press charges for assault. $\mathrm{O}_{1}$ asked $\mathrm{C}_{2}$ why they were asked to leave, and $\mathrm{C}_{2}$ told him it was because their friend was sick. $\mathrm{C}_{2}$ then said the bouncer had no reason to choke out his cousin (C1). O1 told $\mathrm{C}_{1}$ and $\mathrm{C}_{2}$ to listen, and told $\mathrm{C}_{2}$ it was apparent $\mathrm{C}_{1}$ was very intoxicated, very argumentative, and unable to keep quiet. $\mathrm{O}_{1}$ then said that $\mathrm{C}_{2}$ was having a hard time not talking over him. O1 then told $\mathrm{C}_{2}$ everyone inside the bar said $\mathrm{C}_{1}$ and his friends had been asked to leave, and everyone had also cited $\mathrm{C} 1$ as the main problem as he refused to leave and said the bouncer would have to make him leave. O1 then told $\mathrm{C}_{2}$ that because the bar is a private establishment, they may ask anyone to leave for any reason. $\mathrm{O}_{1}$ then told $\mathrm{C}_{1}$ and $\mathrm{C}_{2}$ they had to leave. $\mathrm{C}_{1}$ then yelled about being 
choked out, and $\mathrm{O}_{1}$ warned him if he swore at the officers one more time he would be locked up. $\mathrm{C}_{1}$ angrily asked $\mathrm{O}_{1}$ if it was illegal to swear, to which $\mathrm{O}_{1}$ said it was, and $\mathrm{C}_{2}$ told $\mathrm{O}_{1}$ it was not illegal to swear. At this point $\mathrm{O}_{1}$ told the citizens to go. They did not leave, and $\mathrm{C}_{2}$ said he was in the Marine Corps and knew his rights. $\mathrm{O}_{1}$ told $\mathrm{C}_{2}$ he was in the military too, and that just because $\mathrm{C}_{2}$ was in the Marine Corps did not mean he would not get locked up. C1 then said he needed new cops. O1 told $\mathrm{C} 1$ he could either leave or go to jail, and $\mathrm{C} 1$ began to argue about what he would be arrested for. $\mathrm{C}_{2}$ managed to get $\mathrm{C}_{1}$ to walk down the street before the officers arrested him. $\mathrm{C}_{2}$ asked the officers if he could tell them a story, and $\mathrm{O}_{2}$ said no and summarized the situation by telling $\mathrm{C}_{2}$ that $\mathrm{C}_{1}$ was acting like an idiot and everyone in the bar said $\mathrm{C}_{1}$ was asked to leave but refused. O1 said the officers were not having a conversation with $\mathrm{C}_{2}$. The citizens continued to argue with the officers about how $\mathrm{C} 1$ was assaulted, and $\mathrm{O} 1$ continuously asked the citizens to leave. Before leaving $\mathrm{O}_{1}$ warned $\mathrm{C}_{1}$ and $\mathrm{C}_{2}$ if they came back that night they would be locked up for trespassing. $\mathrm{C}_{2}$ continued to argue so $\mathrm{O}_{1}$ cuffed him. At this point $\mathrm{C}_{1}$ was also arrested. $\mathrm{C}_{2}$ complained of the handcuffs hurting his wrists and said he was politely asking the officer to remove them. O1 sarcastically asked $\mathrm{C}_{2}$ why he all of a sudden wanted to be polite. $\mathrm{O}_{1}$ frisked $\mathrm{C}_{2}$ in front of his vehicle before putting him in the back seat. $\mathrm{O}_{1}$ returned to the front of the bar and asked $\mathrm{C}_{4}$ (male) to recount what he had seen. $\mathrm{C}_{4}$ told the $\mathrm{O}_{1}$ approximately the same story $\mathrm{O}_{1}$ had already heard, but included that $\mathrm{C}_{1}$ had ripped his shirt off and spit on a girl. O1 thanked $\mathrm{C}_{4}$ and returned to his car to leave with $\mathrm{C}_{2}$ in custody.

After arriving at the police station $\mathrm{C}_{2}$ continued to argue with $\mathrm{O}_{1}$, and $\mathrm{O}_{1}$ refused to listen and told $\mathrm{C}_{2}$ to shut his mouth.

Officers are doubtless challenged to act with procedural justice in an emotionally charged situation, and with people who are intoxicated and not entirely in control of themselves. The officers' patience is severely tested in this incident. The procedural justice scale score was 1.5; procedural injustice was 8.5.

\section{A MODEL OF PROCEDURAL JUSTICE IN ACTION}

We can describe more succinctly the respects in which procedural justice and injustice are shaped by the characteristics of the situations in which officers become involved and the citizens with whom they interact, and we can better isolate the independent effects that these factors have on officers' behavior. Previous research (see especially Mastrofski, Jonathan-Zamir, et al. 2016) would lead us to hypothesize that the (in)justice with which police act is influenced by:

- The race, ethnicity, sex, age, and social status of the citizen;

- The role that the citizen plays in the encounter-for example, as suspect, victim/ complainant, or something else (a third party);

- Indications of mental disorder or intoxication, which affect the citizen's capacity for communication and rational behavior; 
TABLE 4 Regression Analysis of Procedurally Just and Unjust Action Scales

\begin{tabular}{lcc}
\hline & Procedurally Just Action Scale & Procedurally Unjust Action Scale \\
\hline Constant & $5.83^{*}$ & 0.06 \\
Citizen a suspect & $-1.20^{*}$ & $0.65^{*}$ \\
Citizen a third party & $-4.64^{*}$ & $0.64^{*}$ \\
Citizen resistance: passive & -0.68 & $1.87^{*}$ \\
Citizen resistance: defensive & $-3.49^{*}$ & 0.44 \\
Citizen resistance: aggressive & -0.17 & 0.28 \\
Citizen disrespect & 0.60 & $0.76^{*}$ \\
Citizen mentally disordered & -0.98 & 0.56 \\
Citizen mildly intoxicated & -0.10 & $0.62^{* *}$ \\
Citizen very intoxicated & -0.15 & -0.07 \\
Citizen male & -0.25 & $0.23^{* *}$ \\
Citizen's age & 0.01 & 0.00 \\
Citizen Black & $0.73^{* *}$ & $-0.34^{*}$ \\
Citizen Hispanic & -0.74 & -0.06 \\
Citizen's education & 0.12 & -0.08 \\
Citizen employed & 0.27 & 0.04 \\
Other citizen present & 0.18 & 0.09 \\
Police-initiated & 0.24 & -0.07 \\
Evidence & 0.24 & 0.02 \\
Neighborhood disadvantage & 0.05 & 0.08 \\
Platoon 2 & 0.43 & 0.01 \\
Platoon 3 & 0.19 & 0.15 \\
Call: violent crime & $1.70^{*}$ & 0.50 \\
Call: nonviolent crime & 0.23 & 0.12 \\
Call: interpersonal conflict & $1.07^{*}$ & 0.13 \\
Call: suspicious circumstance & $-1.34^{* *}$ & 0.34 \\
Call: traffic & 0.48 & 0.26 \\
Call: dependent person & 0.47 & 0.23 \\
Call: assistance & -0.42 & 0.27 \\
Adjusted R & 0.15 & \\
\hline & & \\
& &
\end{tabular}

NOTE: Weighted results

${ }^{*} \mathrm{p}<.05$

$* * \mathrm{p}<.10$

- Citizen resistance and/or disrespect for police;

- The nature of the problem;

- Whether the encounter was initiated by police or a citizen;

- Evidence of criminal wrongdoing.

Operationalizing these variables (excepting the initiation of the encounter) with the observational data, we find that a number of these hypotheses are supported. See table 4 above. ${ }^{21}$

Procedural justice is greater when the situation involves a violent crime or interpersonal conflict, and when the citizen is black. Procedural justice is lower 
when the citizen is a suspect or a third party, and when the citizen defensively resists police authority. Procedural injustice is greater when the citizen is a suspect, a male, disrespectful, or passively resists police authority. Procedural injustice is lower when the citizen is black.

The citizen's role in the encounter has a clear bearing on how officers act. Suspects, relative to victims and complainants, are accorded less procedural justice and greater procedural injustice, even holding constant the actions-resistance or disrespect-or conditions-mental disorder or intoxication-that might be expected to affect officers' behavior. Third parties are shown lower levels of procedural justice, presumably because they are given less attention.

Treating resistance and disrespect as factors to which police respond, resistance matters, but different forms of resistance affect procedural justice and injustice differently. Defensive resistance evokes lower levels of procedural justice, while passive resistance evokes greater procedural injustice, even controlling for disrespect. Disrespect evokes greater procedural injustice, but does not have a detectable effect on procedural justice.

Black citizens, compared with whites, are treated better on both dimensions of police behavior: other things being equal, blacks are accorded greater procedural justice and less procedural injustice. These estimated effects are in the unexpected direction, and they defy our attempts to account for them.

\section{SUMMARY AND CONCLUSIONS}

Building on previous observational research on the police, we formed measures of police behavior that capture the elements of procedural justice. We formed separate measures of procedural justice and procedural injustice, allowing for officers to exhibit either or both in a police-citizen encounter, and also allowing for the possibility that the effects of procedural justice on citizens' subjective experience (which we estimate in the next chapter) would differ from the effects of procedural injustice not only in direction but also magnitude.

The construction of each of these two measures proceeded first by forming a subscale for each of the domains of procedural justice: voice/participation; quality of treatment; neutrality; and trustworthy motives. We classified officers' actions, as observers coded them, in terms of these domains, and we assessed the level of consistency between observers by calculating the intraclass correlation for each subscale. We formed scales of procedural justice and procedural injustice, respectively, by summing the subscale scores for each observer, and we estimated the intraclass correlations of the summed scales ( 0.70 or higher). We constructed these measures to capture the behavior of the primary officer and other officers toward the primary citizen - the citizen whom we interviewed about the encounter-and we also constructed measures of the procedural justice and injustice with which officers acted toward other citizens in the encounter. 
We examined the mean and distribution of each of the two scales in all contacts and in the three types of contacts, finding differences of the expected nature: higher levels of procedural justice in calls than in arrests or field interviews, and higher levels of procedural injustice in arrests and field interviews than in calls for service.

We also formed measures of other actions by officers that might affect citizens' subjective experiences, including the use of verbal or physical force, respectively, searches and frisks of citizens, and searches of citizens' vehicles. We formed measures of the context in which police took action, including the availability and strength of evidence of criminal wrongdoing, resistance by the citizen, and disrespect of the police, and we found the expected patterns of procedural justice and injustice across these contexts, for example, greater procedural injustice when citizens are disrespectful to the police.

Finally, we estimated the parameters of a regression model that includes the factors that previous research suggests might affect procedural justice, finding that procedural justice and injustice bear readily interpretable relationships to a number of situational factors. These analyses offer further evidence that the scales of procedural justice and injustice are valid measures.

With these measures of procedural justice and injustice, derived through observations by trained observers and independent of citizens' survey responses, we are prepared to examine citizens' subjective experience in terms of officers' behavior. To that examination we turn in chapter 7 . 